\title{
Corrigendum
}

\section{Corrigendum to "Thermal Environment and Aeroheating Mechanism of Protuberances on Mars Entry Capsule”}

\author{
Wenbo Miao $\mathbb{D}^{1,2}$ Qi Li, ${ }^{3}$ Junhong Li, ${ }^{1,2}$ Jingyun Zhou, ${ }^{1}$ and Xiaoli Cheng ${ }^{1,2}$ \\ ${ }^{1}$ China Academy of Aerospace Aerodynamics, PO BOX 7201, Sub PO BOX 16, Beijing 100074, China \\ ${ }^{2}$ Key Laboratory of Aero-Thermal Protection of Aerospace Vehicles, China Aerospace Science and Technology Corporation, \\ Beijing 100074, China \\ ${ }^{3}$ Beijing Institute of Spacecraft System Engineering, China
}

Correspondence should be addressed to Wenbo Miao; tingles@126.com

Received 21 December 2021; Accepted 21 December 2021; Published 20 January 2022

Copyright (C) 2022 Wenbo Miao et al. Exclusive Licensee Beijing Institute of Technology Press. Distributed under a Creative Commons Attribution License (CC BY 4.0).

In the article titled "Thermal Environment and Aeroheating Mechanism of Protuberances on Mars Entry Capsule" [1], there was an error in the author name details. The first name and surname of all authors were transposed. The correct author names are shown below, and they are corrected in the author list:

(1) Wenbo Miao

(2) Qi Li

(3) Junhong $\mathrm{Li}$

(4) Jingyun Zhou

(5) Xiaoli Cheng.

\section{References}

[1] M. Wenbo, L. Qi, L. Junhong, Z. Jingyun, and C. Xiaoli, “Thermal environment and aeroheating mechanism of protuberances on mars entry capsule," Space: Science \& Technology, vol. 2021, article 9754068, 8 pages, 2021. 